\title{
Introduction: Young women in Europe in the era of 'first-wave' feminisms: analyses of generation and gender
}

\author{
MARY JO MAYNES*
}

During the course of the nineteenth century, the parameters defining 'youth', marking its beginning and its end, were becoming more precise and more institutionally defined for both girls and boys in Europe. More than any other phenomenon or institution, elementary schooling (and leaving school) contributed to a certain 'normalization' of the life cycle for young people. By the end of the nineteenth century, most girls as well as boys attended school at least intermittently until at least age 12 or 13; at school-leaving a new phase of life began. Throughout much of Europe a select minority of middle-class and upper-class young women joined their brothers at universities, as higher education became first a possibility and then a routine for them in the last decades of the nineteenth and the first decades of the twentieth century.

If educational institutions played a key role in creating more uniform patterns in the life cycle of young people, new cultural and scientific discourses emerging in the late nineteenth century also contributed to a redefinition of youth as a stage in life. Much of the late-nineteenth-century concern about youth initially centred on young men. The poor health of young men inducted into the military alarmed state authorities. The violence of street gangs in working-class neighbourhoods was increasingly seen as a social problem, as were stress and the suicide rates amongst male students. However, new employment opportunities for girls, the campaigns of the women's movements for better education and vocational training for them, and the decreasing birth rate, led to interest in female youth as

\footnotetext{
* Department of History, University of Minnesota.
} 
well. The transition from childhood to young womanhood was increasingly understood, amongst experts at least, in biological, medical, and psychological terms, to an extent much greater than their discussion of boys' transition from childhood to young manhood. By the early twentieth century, new perceptions of female youth would transcend the boundaries of expert discourse and increasingly inform broader understandings of female coming-of-age.

The reshaping of female adolescence was not merely a product of the writings of physicians, social workers, and other experts. Simultaneous changes in the labour market also functioned to alter girls' options and call public attention to female youth as a social category. While most girls continued to spend their youth working on farms, in workshops and factories, or as domestic servants in private homes, by 1900 a growing proportion of girls and young, unmarried women made their way into commerce and the service sector. While some contemporaries lamented girls' flight from rural labour and domestic service, others were more alarmed by their increased earnings and their gradual acquisition of leisure time.

The writing of the history of youth in Europe also began with boys. But the essays grouped together here result from the larger flourishing of the history of women and gender. They take as their focus the history of young women, gender, and generational experiences in Europe between roughly 1880 and 1930 . While each has a different specific focusElizabeth Jones discusses young women farm workers in Saxony; Marynel Ryan looks at the first generation of women to earn advanced degrees in social sciences in Berlin and Paris; and Birgitte Søland analyses women's memoir accounts of growing up working-class in Denmark their contributions work nicely together to call attention to the interplay of social structure, institutions, and discourses. All three studies, moreover, shed new light on how understandings about female youth migrated across social-class boundaries and moved between the realms of expert discourse and personal aspirations.

These essays point to striking novelties in the experiences of female youth around 1900. Certainly the epithet 'New Woman' seems appropriate for the pioneers discussed by Ryan, who were among the first European women to take $\mathrm{PhD}$ degrees in political economy or law, the first to be in positions where they could apply feminist ideas in the realm of welfare policy or labour relations. But Jones suggests that the young women farm workers who ran away from harsh masters sought better alternatives than their mothers had had, and in the process contributed to government concerns about depopulation and rural flight, may have been manifesting something of the same generational spirit. Søland, by 
comparing the memoirs of females' coming-of-age in three different largely urban working-class cohorts in Denmark, argues more precisely that important changes in expectations about growing up female seem to have taken place between 1900 and 1920 or so.

All three studies make arguments based on their authors' reading of typical social-historical sources and discourse analysis. Ryan's analysis looks at the interplay between two different rhetorics of feminism - one based on 'essence' and one based on 'expertise' - as they operated in the different institutional settings of higher education and policy in Berlin and Paris. Søland plays off changing memoir accounts of female youth against historical records that suggest somewhat more continuous workforce and family experiences. Jones looks not just at government statistics and expert studies, but at the courtroom testimonies of runaway farm maids to examine the nature of 'rural flight' as it emerges from quite different points of view. Each article separately is provocative and original. Together they demonstrate how the intersection of gender and generational analysis illuminates not only those two arenas of history but also broader phenomena such as labour history, the history of leisure, the process of professionalization, and aspects of economic and political development. 